\title{
Red Centroamericana de Antropología: encuentro intermedio
}

María Dolores Álvarez Arzate

Con el objetivo de aprobar la convocatoria del XI Congreso Centroamericano de Antropología, "La Antropología Centroamericana: estado actual y proyección futura", miembros dela Red Centroamericana de Antropología realizaron una sesión de trabajo intermedia en la UNAN-MANAGUA. La reunión de la Red, de la que forman parte Panamá, Costa Rica, Nicaragua, Honduras, El Salvador, Guatemala y México, se realizó en abril de 2016. Durante el evento se hizo uso de herramientas como la plataforma virtual Web Ex para videoconferencia.

Estas reuniones intermedias se realizan de manera sistemática en los periodos entre congresos, con el fin de aprobar las convocatorias de los sub-siguientes congresos. Por tanto, se acordó que el congreso siguiente se efectuará en Costa Rica, entre el 27 de febrero y el 3 de marzo de 2017.

La Red se creó en 1994 con el propósito de sumar esfuerzos de intercambio académico y profundizar lazos de colaboración de las diferentes universidades y centros de investigación que poseen programas académicos de grado y posgrado en las distintas especialidades de la Antropología.

Los congresos son espacios que han crecido y fortalecido a partir de la presentación de investigaciones académicas, libros, documentales y materiales en una variedad de formatos. Representa una suma de esfuerzos de los estudios especializados sobre nuestras culturas y sociedades.

En la actualidad, las instituciones activas en la Red son: Universidad de Panamá,
Universidad de Costa Rica, Universidad Nacional Autónoma de Nicaragua, Universidad Nacional Autónoma de Honduras, Universidad Pedagógica Nacional Francisco Morazán, Universidad de El Salvador, Universidad Tecnológica de El Salvador, Universidad de San Carlos de Guatemala, Universidad Nacional Autónoma de México, a través del Centro de Investigaciones Multidisciplinarias sobre Chiapas y la Frontera Sur (CIMSUR), Universidad de Yucatán, Universidad de Quintana Roó, Universidad Veracruzana, y Centro de Investigaciones y Estudios Superiores en Antropología Social México (CIESAS).

La UNAN-Managua, fundadora de la Red, en la actualidad ejerce la Secretaría Ejecutiva (2015-2017) siendo su segundo período consecutivo en este cargo, el anterior fue de 2013-2014. Representa un reconocimiento al liderazgo y presencia en dicho espacio académico internacional. Las representantes por UNAN Managua son la Maestra Maritza Andino, Directora del Departamento de Antropología y Maestra María Dolores Álvarez Arzate, coordinadora de la Maestría en Antropología y Liderazgo Social, del mismo Departamento.

El congreso en Costa Rica de 2017 estará dedicado a reconocidos científicos de la Antropología como Richard Cooke, Ramiro Barrantes Mesén, Adolfo Constela Umaña, y Oscar Fonseca Zamora. Enesta misma reunión intermedia se aprobó un pronunciamiento de apoyo al pueblo lenca en su lucha por la conservación de los territorios ancestrales y sus recursos naturales y en repudio por el asesinato de su líder Berta Cáceres. 
Asimismo, por acuerdo tomado en el $\mathrm{X}$ Congreso Centroamericano de Antropología realizado en Mérida, Yucatán en 2015, la Universidad Nacional Autónoma de Nicaragua UNAN-Managua será la sede del XII Congreso en 2019.

A continuación se dan a conocer una cronología de los Congresos realizados desde su fundación hasta la fecha:

\section{X Congreso Centroamericano} de Antropología "El desarrollo de la Antropología en Centroamérica y el sur de México". Dedicado a Andrés Fábregas Puig y Gladys Casimir. Del 23 al 27 de marzo de 2015. Mérida, Yucatán.

2013. IX Congreso Centroamericano de Antropología "Territorio, recursos naturales y sociedades locales". Dedicado a Carlos René García Escobar y Rolando Quezada Sancho. Del 18 al 22 de febrero 2013. Ciudad de Guatemala, Guatemala.

2011. VIII Congreso Centroamericano de Antropología "Los retos de la antropología en Centroamérica: Identidades, Diversidad Cultural y Procesos Políticos". Dedicado a Anne Chapman. Del 21 al 25 de febrero de 2011. Tegucigalpa, Honduras.

2009. VII Congreso Centroamericano de Antropología "La Antropología en Centroamérica: reflexiones y perspectivas". Dedicado a Otto Schumann Gálvez. Del 16 al 20 de febrero 2009. San Cristóbal de Las Casas, Chiapas, México.
2006. VI Congreso Centroamericano de Antropología "Centroamérica hacia la transformación sociocultural". Dedicado a Alejandro Dagoberto Marroquín. Del 15 al 18 de agosto de 2006. San Salvador, El Salvador.

2004. V Congreso Centroamericano de Antropología "Construyendo Identidades". Dedicado a Gloria Aracely Mejía y Mariano Miranda Noguera. Del 23 al 27 de febrero de 2004. Managua, Nicaragua.

2002. IV Congreso Centroamericano de Antropología "Por la Construcción de la Paz". Dedicado a Carlos Navarrete Cáceres. Del 24 de febrero al 21 de marzo de 2002. Jalapa, Veracruz, México.

2000. III Congreso Centroamericano de Antropología "Reconstruyendo la memoria histórica, hacia el nuevo milenio". Dedicado a Olga Francesca Linares. Del 28 de febrero al 3 de marzo del 2000. Ciudad de Panamá, Panamá.

1997. II Congreso Centroamericano de Antropología, Chiapas, Panamá y Belice. Dedicado a Joaquín Noval y Francisco Rodríguez Rouanet. Del 6 al 10 de octubre. Ciudad Guatemala, Guatemala.

1994. I Congreso Centroamericano de Antropología "Centroamérica ante el cambio global: Identidades, etnicidad y violencia". Dedicado a Segundo Montes. Del 3 al 7 de octubre de 1994. San José, Costa Rica. 